Mobile fathering: absence and presence of fathers in the petroleum sector in Norway

Marit Aure*

Department of Social Science,

UIT The Arctic University of Norway,

Post Box 5060 Langnes,

9037 Tromsø, Norway

004741240034

marit.aure@uit.no

Orcid ID: https://orcid.org/0000-0002-2529-125X

Ackn: Y

CN: Y

Word count: 7151 


\title{
Mobile fathering: absence and presence of fathers in the petroleum sector in Norway
}

\author{
Abstract \\ This article examines the fathering practices of men in mobile work in the \\ petroleum industry in Norway. In particular, it analyses the spatial mobility of \\ these men and how their absence and presence impact their fathering. Drawing \\ on insights from gendered migration and mobility studies, fathering and 'new \\ material' approaches, this article nuances the understanding of current fathering \\ practices by showing how physical absence does not necessarily imply emotional \\ absence and by identifying changing fathering practices among skilled working- \\ class men. This study also suggests that these fathering practices challenge \\ dominant ideas of parenting, which tend to be based on studies of mothering \\ practices. This study uses life course interviews, observations and 'travel along' \\ experiences. The findings demonstrate that being attentive to absence and \\ presence, the agency of materialities, gender and fathers' perspectives may \\ broaden our understanding of fathering in mobile work and beyond.
}

Keywords: class; fathering matrix; parenting; proximity and distance; skilled workers; work-related mobility

\section{Introduction}

As I, a researcher conducting fieldwork, pass Roger (34) in the common room at the guesthouse where he stays while at work, he is about to say goodnight to his son on Skype. Roger is the father of two small children, and for years, he has worked the common 'two-four' offshore rotation on platforms in the Norwegian Sea. This schedule means that he works 12-hour shifts for 2 weeks, followed by 4 weeks off. While workrelated mobility takes Roger away from his family, it also enables prolonged periods at home and subsequent involvement in his children's lives. According to Roger, fathering is about 'doing things together'. Work-related mobility raises particular questions about absence and presence in fathering practices. Petroleum activities account for 8-9 per 
cent of all employment in Norway, with 10 per cent of workers working offshore on a permanent basis. Among these workers, 80 per cent are skilled or high-skilled men. In Norway, the earnings offshore are approximately 30 per cent higher than they are in general manufacturing; hence, working offshore is well paid (Blomgren et al. 2015). Mobility shapes gender, and gender shapes mobility (Hanson 2010) and impact the 'cultural coding of men as fathers (Hobson and Morgan 2002, 9-10). Since fathering is situated in places and temporalities (Marsiglio, Roy, and Fox 2005), mobilities have no universal effects on fatherhood (Lamb 2008, 18). However, there has been limited attention to both the spatial formation of masculinities (Hopkins and Noble 2009; van Hoven and Hörschelmann 2005) and mobility in contemporary fatherhood (Meah and Jackson 2016). Understanding mobile men's fathering requires perspectives that view mobility as central and 'normal' (Sheller and Urry 2006) gendered processes (Cresswell, Dorow, and Roseman 2016; Walsh et al. 2013). Drawing on qualitative data from a study of fathers working in the petroleum industry in Norway, this article analyses the impact of absence and presence on fathering practices. This article proposes a theoretical approach: a matrix of fathering that draws on insights from migration and mobility studies, fathering studies and 'new material' approaches. It argues that attention to different components of parental involvement and fathers' own experiences contributes to a nuanced understanding of fathering practices by showing how physical absence does not necessarily imply emotional absence. By focusing on socio-emotional aspects, activities and the agency of materialities and structures in men's parenting, this article also challenges dominant ideas of parenting as mainly mothers' domain. Before presenting the 'matrix', I briefly examine mobile fathering from the perspective of transnational and mobility studies. I subsequently explain the methodological approach before analysing fathering practices and emphasising the 
significance of the theoretical approach.

\section{What do we know about mobile fathering?}

While the literature on mobile men's fathering is scant, studies of transnationalism offer perspectives on parenting at a distance (Hondagneu-Sotelo and Avila 1997; Parrenas 2001). In comparisons of transnational mothers and fathers, research tends to reduce fathers' roles to economic provision for children, while mothers' roles are portrayed as more complex, including emotional support and care management from afar (Dreby 2006; Parreñas 2008; Pribilsky 2012). Kilkey, Plomien, and Perrons $(2014,178)$. However, focus on the 'parallels between migrant mothering and fathering' emphasise how fathering may also be vital to migrant men. Their study agrees with former studies that propose that transnational parenting is embedded in the gendered division of labour in parents' countries of origin. Parreñas (2001) and later studies show that such ideologies may lead to distress and intensive transnational mothering. Although some studies report on fathers' stress related to being away from their children (Dreby 2006; Schmalzbauer 2015), few studies analyse men's emotions. Emphasising the gender differences between mothers and fathers and focusing on mothers hence risk exaggerating the disparities between the parents and universalising fathering. Furthermore, the lack of a theoretical model of parenting (e.g., Eydal and Rosgaard 2015; Lamb et al. 1987) in many migration studies prevents them from discussing various aspects of parenting, while conflating gender with women prevents focus on masculinity, e.g. shifting understandings from orthodox to more inclusive masculinities embracing emotions etc. (Andersen 2009). Moreover, although studies state that the legal situation of the absent parent affects parenting (Datta et al. 2009; Dreby 2006; Dyer, McDowell, and Batnitzky 2011; McIlwaine 2010; Pribilsky 2012), they rarely describe how it impacts fathering (with the exceptions of Kilkey, Plomien, and Perrons 
2014; Schmalzbauer 2015). The legal situation also highlights the difference between the precarious positions of many migrant parents (Datta et al. 2009) and the somewhat privileged positions of mobile petroleum workers granted by the tripartite (state, union and employers)-regulated Norwegian petroleum industry (Ryggvik 2015). Meanwhile, parenting studies show a strong relation between fathering and class (Brandth and Kvande 1998; Farstad and Stefansen 2015). Class is also important in transnational parenting (Carling, Menjívar, and Schmalzbauer 2012), yet, this literature mainly discusses class in terms of changing class position, with class in fathering passes unnoticed. Information and communication technologies (ICTs) maintain transnational relations and allow people to connect and confirm relationships at a distance (Carling, Menjívar, and Schmalzbauer 2012, 203). ICTs allow mothers to micro-manage their families from afar (e.g., Parreñas 2001, 2008); however, few studies focus on fathering and ICTs. '[T]he experiences of leaving and being left underpin moralities of transnationalism', according to Carling, Menjívar, and Schmalzbauer (2012, 205), and again, studies tend to attend to mothers' moral obligations and leaves fathers' moral obligations unexplored. Moreover, while Pribilsky $(2012,326)$ discusses fathering away and at home, most studies focus on fathering from afar (Dreby 2006; Dyer, McDowell, and Batnitzky 2011; Kilkey, Plomien, and Perrons 2014) and neglect the dynamics between fathering 'here' and 'there'. The transnational parenting literature, seems to miss the intersection of masculinity, mobility and reproduction, and although the transnational parenting literature concludes that physical absence is compatible with social presence (Carling, Menjívar, and Schmalzbauer 2012), this conclusion is not established for fathers. The next paragraph considers the emerging literature on fathering in work-related mobility. 
Zvonkovic et al. (2005) indicate how family networks compensate for the absence of fathers, while Faber et al. (2008) discuss the ambiguities of absence and presence for military families, emphasising that specific types of mobilities require specific forms of attention. While neither of these studies highlights fathers' experiences, Willerton et al. (2011) analyse military fathers from the men's perspectives. These authors (drawing on Palkovitz 1997) distinguish between father's direct and indirect involvement. Sayers and Fox (2005) study long-haul trucking fathers and find that telephone contact with their family is extremely important in fathering 'on the road'. Moreover, Aure and Munkejord (2016) identify changing masculinities among mobile men in Norway and show how these fathers seem to embrace an emerging non-dominant, equality-oriented masculinity. The next section suggests that 'materialist'-inspired approaches may further expand fathering studies.

ICTs impact mobile families in different ways. The actor network-inspired study by Bettany, Kerrane, and Hogg (2014) examines how caring technologies (i.e., monitors) co-enable new fathering roles; simultaneously, it reveals how technology may create tensions and have clear limitations (see also Bell 2001). Pini and Mayes (2012) analyse how a website for the families of mobile mining men may facilitate emotional adjustment and coping with absent husbands and fathers, while Gerrard (2013) shows how various mobilities, materialities and technologies in fisheries impact the fishermen family. Emerging studies on emotions and embodied fathering such as Doucet (2013, 299; see also Aitken 2009) view fathering as 'shifting material discursive intra-actions' of entangled bodies, meanings and objects, and they emphasise the diverse affects of fathering and how such approaches expand current understandings of fathering. This brief assessment has demonstrated the lack of attention to and limited exploration of 
mobile fathering, the necessity of men's perspectives, the inclusion of spatiality and class, and the potential for granting agency to technologies and non-human actors.

\section{The theoretical approach}

Eydal and Rosgaard $(2015,12)$ describe fathering based on five intertwined components: 1) engagement (direct contact); 2) availability to the child; and 3) responsibility for the welfare and care of the child. To these three components originally suggested by Lamb et al. (1987), they add 4) quantity versus quality of time and 5) the father relative to the mother with regard to absolute modes of paternal involvement. The distinction between engagement, availability and responsibility incorporates the shift towards involved fathering and caring masculinities (Brandth and Kvande 1998; Palkovitz 1997), which includes presence at birth, involvement with infants, daughters and sons, and day-to-day childcare, etc. (Ranson 2001). While the five categories implicitly relate to absence and presence, understanding mobile fathering in context requires an explicit spatial dimension. Hence, I add spatiality as a geographical 'depth' to each of the components. In addition, as 'new materialist' studies show, non-human agency, affects and embodiment highlight how fathering is constructed in relation to technologies, embodied skills and values, etc. This constructedness emphasises class and the intersection of class and other forms of differentiation in fathering practices, while the construction and effect of gender and masculinity needs emphasise moving beyond gender as a difference between mothers and fathers. I hence suggest that a contextual understanding of fathering requires that the five components of parental involvement intersect with the spatiality of distance and proximity, the agency, effect and affect of materialities, and gender, which can then be viewed as dimensions forming a multi-dimensional matrix. The remaining part of the article illustrates this matrix by drawing on my empirical data. First, however, I introduce the methodological 
considerations of this study.

\section{Materials and methods}

This study draws mainly on qualitative, semi-structured interviews and two cases of a 'travel along' where I travelled together on planes and buses with two men until they boarded the helicopter to go offshore to work. The 11 interviewed fathers included in this study worked offshore rotations. While I recognise that the men's wives would provide useful information, this article is concerned with men's perspectives. The men were selected from a broader study on mobile work in the petroleum industry with approximately 60 participants because they are fathers who work or have worked on 2-4 rotations. Some of this material formed part of an impact study on the Eni Norway AS Goliat project. I also recruited informants through snowball sampling from initial contacts with recruitment officers and personal contacts in petroleum and petroleum service companies. The interviews lasted between one and two hours and were audiorecorded, partly transcribed by the author and supplemented with extensive written notes from the interviews. The interviews occurred in working hours at workplaces/canteens and in private homes and guesthouses. The ethnographic material from the travel along is captured in field notes. The participants were between 23 and 65 years old and had from one to four children who ranged in age from one month to adult age. Except for two, all the men lived with the mother of their children in longterm relationships. The participants came from various urban and rural backgrounds in Norway, and all of them have craftsman certificates; a few had later obtained higher education and worked either as skilled workers or as managers. Regardless of current position, they all express a working-class identity 'as an ordinary working man', while they are also proud and outspoken about their income. The men are given pseudonyms, and additional information about them is scant to ensure their anonymity. I used life 
course interviews in this study. This invites coherent narratives and gives access to the narrators' self-presentation. To extend this I encouraged the participants to share concrete accounts of ordinary and exceptional fathering practices, everyday routines at home and at work, household tasks, childcare, and gender divisions, and I asked for challenges in work-related mobility. The men talked personally about marital conflicts, infidelity, shame and loneliness. However, they presented somewhat positive accounts of their mobile livelihood and fathering practices and seemed to enjoy the opportunity to share their views due to the feeling that their mobile fathering is contested and missing in public discussions.

I first analysed the interviews and observations inductively by searching for important themes 'along and across' the life course stories, followed by an approach inspired by previous studies and the theoretical approach that I developed. Hence, the fathering matrix presented above grew out of the dialogues between my data and previous research as a form of constructionist grounded theory (Charmaz 2006). The analysis focuses on the entangled fathering 'away' before moving to fathering at home, based on an important empirical distinction.

\section{Results}

\section{Involved - yet away}

According to Roger,

...the 'two-four' is the dream rotation. You are basically working for 4 months, staying at home for 8 months a year. The hard thing is that I miss out on Christmas, birthdays, the first step... and the children or my wife being sick. I just cannot think about it; it is the way it is. What can you do? You have to work. 
Roger finds it difficult to be away when something 'is going on at home', which is always the case when you have children, he says, identifying a main dilemma in mobile work. Roger talks with his family, shares their worries and is accessible through ICTs, but some costs cannot be avoided by technology, as shown by Bell (2001) for divorced fathers. Roger is mentally engaged in his family (Palkovitz 1997; Willerton et al. 2011) but feels helpless when he misses their everyday struggles and fails to 'do his share'; absence challenges his accountability as a father and as a man. The distance (thousands of $\mathrm{km}$ ) and location (offshore), the helicopter ride to the platform and the duration of the rotation, implying two full weeks away, make the men unavailable and restrict the family's shared life. According to Arthur (48, two adult children, electrician with additional education), his inability to share his former wife's everyday life contributed to their divorce: Her experiences as a periodically 'single' working mom with small children widely differed from his work away and his experiences as a dad periodically staying at home, full time.

However, several participants, such as Roger, Arne (49, two teenage children, process operator) Arthur and Carl (52, automatician, two teenage children), disclose how daily phone calls enable them to help rearrange the family schedule at home in case of sickness, organise help, and engage emotionally. This parallels the practice of transnational mothers (Carling, Menjívar, and Schmalzbauer 2012; Dreby 2006; Parrenas 2001) but are rarely reported for fathers. While the empirical material does not give information on the frequencies of such incidents, this type of engagement presupposes a familiarity with the family's needs, social network and the ability to act accordingly at a distance. The spatial absence restricts mobile fathers but they can still be emotionally and practically accessible: Arne's 14-year-old son does not like school much and seems to be depressed. Arne has hence scheduled their next parent meeting 
with the school during his upcoming time off. He invites his son to share his own interest in old American cars, and now, he says, they Skype several times a day while Arne is offshore to discuss which car to buy and what spare parts to acquire. Arne involves his friends in his son's problems and their 'car project', and according to him, the project gives them 'something to talk about and a reason to hang out together'. This skillset and circle of friends are the tools that Arne has at hand, and they give him 'access' to his son. This interest in cars is an entangled masculine resource associated with both Arne's trade and working-class culture. Arne's practice resembles intensive mothering (Parrenas 2001) due to the extensive contact and engagement while away but differs due to the skills, masculinity and personal interests involved and its orientation towards doing things together, rather than 'parental care' activities.

Similar to Roger, several of the participants negotiate the costs of their absence from their families in terms of the statement 'you have to work'. This utterance relates to their economic provision for the family, considered at the core of masculinity and fathering (Dyer, McDowell, and Batnitzky 2011; Lamb et al. 1987) and to the Nordic welfare state model, which is based on the fact that most women and men are engaged in the labour market (Rugkåsa 2012). However, fathering is not limited to economic provision; fathers are also involved practically and emotionally, which relates to fathering norms of caring masculinities (Aure and Munkejord 2016; Brandth 2016). While Anderson (2009) describes a shift from orthodox to inclusive masculinities, I suggest that these types of masculinity intersect: Economic provision negotiates mobile men's absence but does not compensate for emotional engagement: both are required in this masculinity. Additionally, the participants' absence makes them dependent on people who are present at home. This dependence may challenge their masculine independence and must be balanced out economically and socially, mostly at home. 
The inaccessibility to family of offshore installations also restricts the family's involvement with the men's work. This may create isolation for the men. Carl, whose children are now young adults, says, 'The family has no ideas what it's like here. When the children were small, they loved when I came home and cried when I left. Now, they hardly notice'. Both Carl and Arne worry about whether they are present in their children's and partner's minds. As echoed by other men, Arne says that leaving is sometimes worse, because he is inflicting this livelihood and vulnerability on his family.

ICTs enable both direct involvement with children and shared responsibility; however, this engagement depends on the children's age and gender (Carling, Menjívar, and Schmalzbauer 2012). Several men explain how difficult it is to maintain contact with their daughters as they grow older. While Roger primarily uses Skype with his children, phone and text shorter information to his wife, Arne proudly shows the Instagram account that enables him to stay in contact with his daughter (aged 16). Many fathers of school-age children ensure that they receive e-mails directly from the school and from clubs about their children's leisure activities. Moreover, e-mail enables Carl to be the accountant of his son's volleyball team, though his regular absence prevents him from coaching the team. John (23), however, describes the struggle to maintain contact with his 1-year-old son while on a four-four rotation in South Korea, which made him and his wife decide not to have another child before his two-four rotation was permanent:

I could only call after work when the little guy was in bed, and when I rose in the morning, he was already in kindergarten. At that age... calling only on the weekends was not sufficient. Being away for 4 weeks was too long; he had to get to know me every time I returned... 
Hence, the duration and rhythm of the rotation, time zones, age, gender, etc. inter-act to produce specific fathering.

The participants' experience of guilt related to their mobile parenting varies. John says that he still has 'a bad conscience about being away $[\ldots]$ even though I was with him a lot'. He feels the tension between work and fathering (Ranson 2001) in the form of guilt. In contrast, Roger is surprised when I ask about feeling guilty for being away. Similar to others, he rejects both that he feels guilt and the relevance of the question. For him, being away for work is, as we have seen, part of the fathers' economic provision. He and other participants view their time and contact with their children as appropriate. Their perspective is in line with the quantitative study of 1,697 shift workers in petroleum by Ljoså and Lau (2009), who show that most workers on 24 rotations feel that they have sufficient time at home. Yonas, who has children who are 14 and 16 years old, holds that 'the children seem to adjust' and seemingly subscribes to a more orthodox fathering. Conversely, Eric (26, father of a new-born child and a toddler) quit his offshore job, is currently on paternity leave, says: 'No way would I continue to work offshore. Younger children need daily contact'. Whereas absent mothers' guilt is well documented (Dreby 2006; Parrenas 2001), these men relate to their absence in various ways. The men are subject to the fathers quota (parental leave), and no indications suggest that their uptake of the quota differs from that of other fathers (Halrynjo and Kitterød 2016). Halrynjo and Kitterød (2016) suggest that the fathers' quota in parental leave constitutes a new norm: John, the youngest participant and the father of an infant, subscribes to this idea: All the fathers whom he knows take the quota. Several of the older fathers had their children at the time when the quota gave them only one trip off (10 weeks at home). Tor (35, process manager and father of two small children) had a prolonged paternal leave due to his wife's illness with their first 
child and the 'full' fathers' quota with their second child. The fathers' quota is spent in different ways, and the involved fatherhood comes in different forms (Brandth and Kvande 2016; Farstad and Stefansen 2015); however, the quota seems to create responsibility (Brandth and Kvande 2016). Hence, the father's quota is a materiality that impacts fathering practically and emotionally. Does it perhaps make younger men more concerned about their absence from their children than older fathers?

Work-related mobility relates to gendered power relations in various ways: Roger's 5-year-old child is currently having difficulties with his father's absence, and Roger's partner is taking some days off from work. 'We can afford it', he says. His wife's boss accepts that she must adjust to Roger's absence and the family's needs, although she was just appointed a middle manager. High wages and geographical distance preserve the gender division of work and Roger's main breadwinning status. They increase the economic imbalance between spouses, support his mobile work, maintain gender hierarchies, masculine accountability and the manner in which fathering is related to mothering. Delays and changes in helicopter and plane schedules are inevitable and add to the prioritising of men's work over women's work. This 'materiality' makes some want to quit the industry, even though, as Eric warns, 'the high wages and amount of time off make it almost impossible to find a comparable job'. While these men are proud to successfully provide for their family and buy motorbikes, boats, large houses, etc., which the family also appreciates, this also ties them and their family to mobile living. However, mobile work has other features: Tor 'enjoy[s] the intense work; I have no worries about housework and being social... and then, - only relaxing, being with the kids, and being my own boss'. While some feel isolated and restricted at work, other men enjoy this compartmentalising, an issue not being discussed in transnational mothering, maybe prevented by gender norms? Finally, 
tripartite negotiations (Ryggvik 2015) produced the regulated rotation of 4 weeks off and the relatively short 2 weeks at work. Hence, unlike most mobile people, these workers are well paid and spend more time at, rather than away from, home. Time at home is the main material moderator of the costs of mobility. The next section analyses fathering 'at home'.

\section{Fathering at home}

Roger takes his children to visit his friends, pours the foundation for the new garage of his brother-in-law and engages both children in the (part-time) work of farm maintenance. He and his children's activities are closely connected to his skills, machinery and tasks, including shopping for groceries and preparing dinner. The long uninterrupted periods at home make it possible for these men to involve their children in housework, etc., which is impossible for most working parents. The time off enables Roger to '...take the kids to kindergarten late and fetch them early, enjoy relaxed mornings, take days off and go for snowmobile trips with them'. Arthur explains how he used to ensure that his children spent only the 'core time' in kindergarten and alludes to a moral dimension of parenting in Norway, prescribing short days in kindergarten and allowing them more time at home (Farstad and Stefansen 2015). This morality negotiates parenting in mobile families and constitutes mobile men as 'good fathers'. Tor takes his children fishing, cleans the house, performs some maintenance work and makes dinner. Arne needs the first day at home to recover: 'After that, I always make breakfast for the family and get their day started, tidy the house, make dinner, and do laundry'. In contrast, Carl was never up first in the morning - he used to fetch the kids at school and performed volunteer maintenance and construction work in the kindergarten. Now that his children are older, he 'helps with homework and drives them to tournaments all around the region'. They all remind me: 'I have the days off, you 
know'. This long presence at home gives the men time to be alone with their children and develop their own relationships, without the mother, which has been found to be vital in involved fathering (Brandth and Kvande 2016; Doucet 2006; Ranson 2001). Some of the men in their fifties emphasise that their activities with their children differ from their children's activities with their mothers; Carl 'counters the 'la-di-da', nondirectional support of the mother'. The younger men also involve their children in their own interests but may not frame doing so in opposition to mothering, again, possibly indicating a change in fathering. Some men also talk less about preparing clothes and performing household tasks than about the tasks that they relate to their own interests: They highlight how they engage their children in their (male-connoted) activities and focus on doing 'things' with their children, denoting a traditional gender division of household labour. Carl's and Arne's narratives of raising their children to 'stand on their own and to do good work' echo their descriptions of their work ethics and of supervising apprentices and gaining confidence in their trade. These contents correspond to masculine working-class activities rather than to children-centred activities (Brandth and Kvande 1998; McDowell 2003). The rotation also provides time for 'kidding around' with their children, which may 'function as a means of emotional engagement, development of capacity for outdoor activities, and teaching children survival skills' (Creighton et al. 2015, 1). Meanwhile, Forsberg (2007, 123) distinguishes between childcare and involvement with children and describes playing a computer game as entailing less responsibility than putting a child to bed. These mobile men's children-involved activities challenge such distinctions and broaden and nuance the seemingly mother-based parenting reported, for instance, in many transnational studies. Mobile men's fathering hence connects across space, time, materialities, class and masculinity. 


\section{Discussion}

\section{The fathering matrix: spaces of involvement}

This section discusses the five components of paternal engagement in relation to distance and proximity, the agency of material 'structures' and emotions, and the integrated gender perspective.

The entanglement of ICTs, routines, and fathering norms and responsibilities across distances makes the fathers be involved directly and indirectly with their children and other people at home while they are away. Therefore, spatial, mental and social absences do not necessarily overlap and should not be conflated. Nevertheless, shared space-time is required for many forms of bodily engagement, and direct non-medial interactions for these fathers at work are limited, while they have substantial time for direct contact with their children at home. This contact is often based on the fathers' interests and is more 'integral' than the 'child as a project' parenting style that is found in middle-class studies (Farstad and Stefansen 2015). It specifies other practices and moves beyond the caring activities that Ranson (2001) defines as involved fathering. The constellations of absence, presence, the gendered skills, activities and objects that are involved may extend stereotypical ideas of fathering and indicate a changing orthodox yet involved fathering.

While they are away at work, these fathers' physical availability is restricted. Similar to parents who work close to home, they can be reached through ICTs. Nevertheless, they lack spatial availability to a greater extent than most parents, especially regarding incidents that require immediate spatial accessibility. However, availability for children also require time and mental presence and depends on trust, common interests and the ability to engage with one another. This accessibility can be maintained distally. The periods of entire days off make these fathers accessible at 
home and allow them to surpass the time restrictions that parents 'close to home' experience, although neither type of parent is always accessible to children. Thus, questions of availability are entangled in gender, time, space, materiality and activities.

By successfully providing high material standards, these fathers feel that they have fulfilled some core responsibilities. Brannen and Nilsen (2006) indicate a shift from 'fatherhood' as economic provision to 'fathering' as caring; however, this study finds that the men view themselves as providers and caring fathers, with their absence for work as a consequence thereof. These men's pride in being successful providers and skilled workers relates to class (Farstad and Stefansen 2015; McDowell 2003), and the implicated gendered division of labour makes the women at home adjust to the men's work. Material provision includes unpaid work, which is often performed by women. In this study, men also report substantial time performing unpaid (often skilled) work in the household and beyond; they include children in their own activities and demonstrate that the responsibility for welfare and care also involves a cultural assessment of activities. Responsibility thus includes economic and unpaid provisions of labour and activities involved in care that relate to gender and class and that warrant further exploration.

The men tend to emphasise the quantity and accessibility of their time spent at home. They evoke the quality of time to explain their accessibility while at work and downplay the quantity of time away. By living offshore in a harsh climate, they acknowledge the continuous presence and spatial quality of time required to address sudden incidents that are created by their periodic weeks and that their spouses provide. However, they also question the seemingly continuous presence and availability provided when parents work close to home. 
This shows that parenting is relational; fathering relates to mothering. 'Do men mother?', Doucet (2006) asks. Some fathering studies (e.g., Forsberg 2007) and many transnational studies compare mothers and fathers based on seemingly women-oriented standards of fathering practices. This study on men's perspectives does not claim to be a source for assessing men's household participation. However, it suggests that understanding the varieties of parents' involvement requires careful exploration of mothers' and fathers' own experiences, as these are contextual and may differ. This study shows that some men's fathering is closely related to working-class masculinities, and associated to how these men value self-reliance and confidence in mastering skills.

To summarise, the intersection of the agency of technology that enables and limits direct and indirect engagement; regulations and other 'structures'; objects that make mobile work in the petroleum industry a particular case; and the complexity of geographical and mental absence and presence intertwined in gendered processes and power relations makes visible that mobile fathering require examinations in men's own terms. While this format does not permit detailed analyses of the variety of fathering practices, the empirical data illustrate how fathering is situational by showing how this particular group of men father in ways that are not only similar but also different. It also shows the spatially and gendered embeddedness of the concepts of care, involvement and parental relations. An extensive exploration of these concepts in mothering and fathering in various contexts may provide a better understanding of the gendered orthodoxy and fluidity in parenting, related to economics, class, power, norms and ideologies.

This study reveals how the agency of schedules, technologies and skills is actively engaged in constituting mobile fathering practices across absence and presence and captures this entanglement in the proposed fathering matrix. Spatial, mental and 
emotional absence or presence should not be conflated, nor should spatial presence and emotional proximity be conflated. This study extends our understanding of mobilesituated involved fathering and shows fathering that involves paid and unpaid provisions of labour, child care and emotional engagement among these men. This result may be described as varied and changing non-hegemonic, masculine practices of orthodox yet involved fathering. However, mobile work maintains the patterns of the economic subordination of women because of the priority of men's work over women's economic work based on women's everyday presence. Involved fathering opposes and expands the gendered understanding of parenting but not necessarily the gender divisions and inequalities in other fields.

\section{Acknowledgments}

I thank the anonymous reviewers and Mai Munkejord, and the editor for their constructive comments on this article.

\section{Funding}

This work was supported by the Norwegian Research Council under Grant number 214265; Canadian Social Sciences and Humanities Research Council (SSHRC), Partnership Grants Appl.ID 895-2011-1019.

\section{Disclosure statement}

There are no conflicts of interests related to this article.

\section{Notes on Contributor}

Marit Aure is a professor in sociology at UIT The Arctic University of Norway. She holds a $\mathrm{PhD}$ in planning and community studies and applies interdisciplinary approaches in her research on work-related mobility in the petroleum industry, internal and international migration, place and communities. Most of her work involves questions of gender, households, age, ethnicity and intersectionality. Her current interests include innovations in migrant integration, masculinities, intergenerational care and older people, and women in management. Aure 
cooperates with municipalities and associations and publishes in national and international academic journals, newspapers and popular media. She is a partner in the Canadian On the Move Partnership.

\section{References}

Aitken, Stuart. C. 2009. The Awkward Spaces of Fathering. Burlington, VT: Ashgate. Anderson, Eric. 2009. Inclusive Masculinity: The Changing Nature of Masculinities. London, UK: Routledge.

Aure, Marit, and Mai Camilla Munkejord. 2016. "Creating a Man for the Future: A Narrative Analysis of Male in-Migrants and Their Constructions of Masculinities in a Rural Context." Sociologia Ruralis 56 (4): 531-551. doi:10.1111/soru.12111.

Bell, Vikki. 2001. "The Phone, the Father and Other Becomings: On Households (and Theories) that no Longer Hold." Cultural Values 5 (3): 383-402. doi:10.1080/14797580109367238.

Bettany, Shona M., Ben Kerrane, and Margaret K. Hogg. 2014. "The MaterialSemiotics of Fatherhood: The Co-Emergence of Technology and Contemporary Fatherhood." Journal of Business Research 67 (7): 1544-1551. doi:10.1016/j.jbusres.2014.01.012.

Blomgren, Atle, Christian Quale, R. Austnes-Underhaug, Anne Marthe. Harstad, Sveinung Fjose, et al. 2015. "Industribyggerne 2015: En kartlegging av sysselsetting i norske petroleumsrelaterte virksomheter, med et særskilt fokus på leverandørbedriftenes eksportsysselsetting." IRIS report-2015/031.

Brandth, Berit. 2016. "Rural Masculinities and Fathering Practices." Gender, Place \& Culture 23 (3): 435-450. doi:10.1080/0966369x.2015.1013454.

Brandth, Berit and Elin Kvande. 1998. "Masculinity and Child Care: The Reconstruction of Fathering." Sociological Review 46 (2): 293-313. doi:10.1111/1467-954x.00120.

Brandth, Berit and Elin Kvande. 2016. "Masculinity and Fathering Alone during Parental Leave." Men and Masculinities. doi:10.1177/1097184x16652659.

Brannen, Julia and Ann Nilsen. 2006. "From Fatherhood to Fathering: Transmission and Change among British Fathers in Four-Generation Families." Sociology 40 (2): 335-352. doi:10.1177/0038038506062036. 
Carling, Jørgen., Cecilia Menjívar, and Leah. Schmalzbauer. 2012. "Central Themes in the Study of Transnational Parenthood." Journal of Ethnic and Migration Studies 38 (2): 191-217. doi:10.1080/1369183x.2012.646417.

Charmaz, Kathy. 2006. Constructing Grounded Theory: A Practical Guide through Qualitative Analysis. Thousand Oaks, CA: SAGE Publications.

Creighton, Genevieve, Mariana Brussoni, John Oliffe, and Lise Olsen. 2015. "Fathers on Child's Play: Urban and Rural Canadian Perspectives." Men and Masculinities 18 (5): 559-580. doi:10.1177/1097184x14562610.

Cresswell, Tim, Sara Dorow, and Sharon Roseman. 2016. "Putting Mobility Theory to Work: Conceptualizing Employment-Related Geographical Mobility." Environment and Planning A 48 (9): 1787-1803. doi:10.1177/0308518x16649184.

Datta, Kavita, Cathy McIlwaine, Joanna Herbert, Yara Evans, Jon May, and Jane Wills. 2009. "Men on the Move: Narratives of Migration and Work among Low-Paid Migrant Men in London." Social \& Cultural Geography 10 (8): 853-873. doi:10.1080/14649360903305809.

Doucet, Andrea. 2006. Do Men Mother?: Fathering, Care, and Domestic Responsibility. Toronto: University of Toronto Press.

Doucet, Andrea. 2013. "A “Choreography of Becoming”: Fathering, Embodied Care, and New Materialisms." Canadian Review of Sociology 50 (3): 284-305. doi:10.1111/cars.12016.

Dreby, Joanna 2006. "Honor and Virtue: Mexican Parenting in the Transnational Context." Gender \& Society 20 (1): 32-59. doi:10.1177/0891243205282660.

Dyer, Sarah, Linda McDowell, and Adina Batnitzky. 2011. "Migrant Work, Precarious Work-Life Balance: What the Experiences of Migrant Workers in the Service Sector in Greater London Tell us about the Adult Worker Model." Gender, Place \& Culture 18 (5): 685-700. doi:10.1080/0966369x.2011.601808.

Eydal, Guðný Björk, and Tine. Rosgaard. 2015. "Introduction." In Fatherhood in the Nordic Welfare States, edited by Guðný Björk Eydal and Tine Rostgaard, 1-21. Bristol: Polity Press.

Faber, Anthony J., Elaine Willerton, Shelly R. Clymer, Shelly M. MacDermid, and Howard M. Weiss. 2008. "Ambiguous Absence, Ambiguous Presence: A Qualitative Study of Military Reserve Families in Wartime." Journal of Family Psychology 22 (2): 222-230. doi:10.1037/0893-3200.22.2.222. 
Farstad, Gunhild R., and Kari Stefansen. 2015. "Involved Fatherhood in the Nordic Context: Dominant Narratives, Divergent Approaches." Norma 10 (1): 55-70. doi:10.1080/18902138.2015.1013348.

Forsberg, Lucas. 2007. "Negotiating Involved Fatherhood: Household Work, Childcare and Spending Time with Children." Norma 2 (2): 109-126.

Gerrard, Siri. 2013. "Mobilities, Materialities, and Masculinities: Interconnected Mobility Practices in Norwegian Coastal Fisheries." Norwegian Journal of Geography 67 (5): 312-319. doi:10.1080/00291951.2013.847482.

Halrynjo, Sigtona and Ragni H. Kitterød. 2016. Fedrekvoten-Norm for Fedres Permisjonsbruk I Norge og Norden. En Litteraturstudie. Oslo, Norway: Institutt for samfunnsforskning.

Hanson, Susan. 2010. "Gender and Mobility: New Approaches for Informing Sustainability." Gender, Place \& Culture 17 (1): 5-23. doi:10.1080/09663690903498225.

Hobson, Barbara, and David Morgan. 2002. "Introduction." In Making Men into Fathers: Men, Masculinities and the Social Politics of Fatherhood, edited by Barbara Hobson, 1-21. Cambridge, MA: Cambridge University Press.

Hondagneu-Sotelo, Pierette, and Ernestine Avila. 1997. "'I'm Here, but I'm There': The Meanings of Latina Transnational Motherhood." Gender \& Society 11 (5): 548571. doi:10.1177/089124397011005003.

Hopkins, Peter, and Greg Noble. 2009. "Masculinities in Place: Situated Identities, Relations and Intersectionality." Social \& Cultural Geography 10 (8): 811-819. doi:10.1080/14649360903305817.

Kilkey, MMajella, Ania Plomien, and DDiane Perrons. 2014. "Migrant Men's Fathering Narratives, Practices and Projects in National and Transnational Spaces: Recent Polish Male Migrants to London." International Migration 52 (1): 178-191. doi:10.1111/imig. 12046.

Lamb, Michael, Joseph Pleck, Eric Charnov, and James Levine. 1987. "A Biosocial Perspective on Paternal Behavior and Involvement." In Parenting Across the Life Span: Biosocial Dimensions, edited by Jane B. Lancaster, Jeanne Altmann, Alice S. Rossi and Lonnie. R. Sherrod, 111-142. Hawthorne, NY: Aldine de Gruyter.

Lamb, Michael E. 2008. "The Many Faces of Fatherhood: Some Thoughts About Fatherhood and Immigration." In On New Shores: Understanding Immigrant 
Fathers in North America, edited by Shuang S. Chuang and Robert P. Moreno, 7-24. Lanham, MD: Lexington Books.

Ljoså, CathrineH., and BjørLau. 2009. "Shiftwork in the Norwegian Petroleum Industry: Overcoming Difficulties with Family and Social Life-a Cross Sectional Study." Journal of Occupational Medicine and Toxicology 4 (1): 22. doi:10.1186/1745-6673-4-22.

Marsiglio, William, Kevin Roy, and Gree L. Fox. 2005. Situated Fathering: A Focus on Physical and Social Spaces. Boulder, CO: Rowman \& Littlefield Publishers.

McDowell, Linda. 2003. Redundant Masculinities?: Employment Change and White Working Class Youth. Oxford: Blackwell Publishing.

McIlwaine, Cathy. 2010. "Migrant Machismos: Exploring Gender Ideologies and Practices among Latin American Migrants in London from a Multi-Scalar Perspective." Gender, Place \& Culture 17 (3): 281-300. doi:10.1080/09663691003737579.

Meah, Amgela, and Peter Jackson. 2016. "The Complex Landscape of Contemporary Fathering in the UK." Social \& Cultural Geography 17 (4): 491-510. doi:10.1080/14649365.2015.1089586.

Palkovitz, Rob. 1997. "Reconstructing 'Involvement': Expanding Conceptualizations of Men's Caring in Contemporary Families." In Generative Fathering: Beyond Deficit Perspectives, edited by Alan J. Hawkins and David C. Dollahite, 200216. Thousand Oaks, CA: Sage.

Parrenas, Rhacel S. 2001. "Mothering from a Distance: Emotions, Gender, and Intergenerational Relations in Filipino Transnational Families." Feminist Studies 27 (2): 361-390. doi:10.2307/3178765.

Parreñas, Rhacel S. 2008. "Transnational Fathering: Gendered Conflicts, Distant Disciplining and Emotional Gaps." Journal of Ethnic and Migration Studies 34 (7): 1057-1072. doi:10.1080/13691830802230356.

Pini, Barbara, and Robyn. Mayes. 2012. "Gender, Emotions and Fly-in Fly-out Work." Australian Journal of Social Issues 47 (1): 71-86. doi:10.1002/j.18394655.2012.tb00235.x.

Pribilsky, Jason. 2004. "'Aprendemos a Convivir': Conjugal Relations, Co-Parenting, and Family Life among Ecuadorian Transnational Migrants in New York and the Ecuadorian Andes." Global Networks 4 (3): 313-334. doi:10.1111/j.14710374.2004.00096.x. 
Pribilsky, Jason. 2012. "Consumption Dilemmas: Tracking Masculinity, Money and Transnational Fatherhood between the Ecuadorian Andes and New York City." Journal of Ethnic and Migration Studies 38 (2): 323-343. doi:10.1080/1369183x.2012.646429.

Ranson, Gillian. 2001. "Men at Work: Change_-or No Change? —in the Era of the 'New Father." Men and Masculinities 4 (1): 3-26. doi:10.1177/1097184x01004001001.

Rugkåsa, Marianne. 2012. Likhetens Dilemma: Om Sivilisering og Intgrasjon i den Velferdsambisiøse Norske Stat. Oslo, Norway: Gyldendal Akademisk.

Ryggvik, Helge. 2015. "A Short History of the Norwegian Oil Industry: From Protected National Champions to Internationally Competitive Multinationals." Business History Review 89 (1): 3-41. doi:10.1017/s0007680515000045.

Sayers, Jeremy P., and Greer L. Fox. 2005. "The Haunted Hero: Fathering Profiles of Long-Haul Truckers." In Situated Fathering: A Focus on Physical and Social Spaces, edited by William Marsiglio, Kevin Roy and Greer L. Fox. Boulder, CO: Rowman \& Littlefield Publishers.

Schmalzbauer, Leah. 2015. "Temporary and Transnational: Gender and Emotion in the Lives of Mexican Guest Worker Fathers." Ethnic and Racial Studies 38 (2): 211-226. doi:10.1080/01419870.2013.857033.

Sheller, Mimi, and John Urry. 2006. "The New Mobilities Paradigm." Environment and Planning A 38 (2): 207-226. doi:10.1068/a37268.

van Hoven, Bettina, and Kathrin Hörschelmann. 2005. Spaces of Masculinities. London, UK: Routledge.

Walsh, Deatra, Halldis Valestrand, Siri Gerrard, and Marit Aure. 2013. "Gendered Mobilities in the North: Advancing an International Comparative Perspective." Norwegian Journal of Geography 67 (5): 260-265. doi:10.1080/00291951.2013.847857.

Willerton, Elaine, Rona L. Schwarz, SShelly M. MacDermid, and Mary S. Oglesby. 2011. "Military Fathers' Perspectives on Involvement." Journal of Family Psychology 25 (4): 521-530. doi:10.1037/a0024511.

Zvonkovic, Anisa M., Catherine R. Solomon, Aime M. Humble, and Maragret Manoogian. 2005. "Family Work and Relationships: Lessons from Families of Men whose Jobs Require Travel." Family Relations 54 (3): 411-422. doi:10.1111/j.1741-3729.2005.00327.x. 